\title{
Phytoplasma-Induced Floral Abnormalities in Catharanthus roseus Are Associated with Phytoplasma Accumulation and Transcript Repression of Floral Organ Identity Genes
}

\author{
Yi-Ting Su, ${ }^{1}$ Jen-Chih Chen, ${ }^{2,3}$ and Chan-Pin Lin ${ }^{1,2}$ \\ ${ }^{1}$ Department of Plant Pathology and Microbiology, National Taiwan University, Taipei, 106, Taiwan, Republic of China; \\ ${ }^{2}$ Institute of Biotechnology, National Taiwan University, Taipei, 106, Taiwan, Republic of China; ${ }^{3}$ Agricultural Biotechnology \\ Research Center, Academia Sinica, Taipei, 106, Taiwan, Republic of China
}

Submitted 30 June 2011. Accepted 6 August 2011.

Floral symptoms caused by phytoplasma largely resemble floral reversion in other plants. Periwinkle leaf yellowing (PLY) phytoplasma and peanut witches'-broom (PnWB) phytoplasma caused different degrees of floral abnormalities on infected periwinkle plants. The PLY phytoplasmainfected plants exhibited floral discoloration, virescence, small flowers, and only occasionally full floral reversion. In contrast, PnWB phytoplasma frequently induced complete floral reversion and resulted in a witches'-broom symptom from the floral reversion. Although different degrees of floral symptoms were induced by these two phytoplasmas, the morphological disorders were similar to those of other plants carrying SEPALLATA mutations or gene silencing. Here, we compared expression levels of organ-identity-related genes and pigmentation genes during floral symptom development. Accumulation of phytoplasmas in malformed flowers and their closely surrounding leaves was also compared. In infected plants, transcript abundance of all examined organ identity genes and pigmentation genes was suppressed. Indeed, CrSEP3, a SEPALLALA3 ortholog, showed the greatest suppression among genes examined. Of the pigmentation genes, transcript reduction of chalcone synthase was most highly correlated with the loss in floral pigmentation. Floral symptom severities were associated with the accumulation of either phytoplasmas. Interestingly, both phytoplasmas accumulated to higher levels in malformed flowers than in their surrounding leaves. Many plant pathogens manipulate host plant development to their advantage. It is intriguing to see whether phytoplasmas alter floral development to increase their population.

Phytoplasmas are wall-less obligate bacterial pathogens that are associated with more than a thousand plant diseases in a few hundred plant species, including economically important crops, and cause yield and quality losses worldwide (Hogenhout

Corresponding author: J.-C. Chen; E-mail: jchchen@ntu.edu.tw; Telephone: +1886233666013 Fax: +1 886233666001 ;

Nucleotide sequences data is available under the following accession numbers: $C r D E F 1$ (HQ343408), CrGLO1 (HQ343409), CrAG1 (HQ343410), $\mathrm{CrSEP3}$ (HQ343411), and $\mathrm{CrCHI}$ (HQ343412).

* The $\boldsymbol{e}$-Xtra logo stands for "electronic extra" and indicates that a supplementary figure is published online. et al. 2008; Lee et al. 2000). They are transmitted by phloemsap-feeding insects, such as leafhoppers, planthoppers, and psyllids, and spread systemically throughout the plant but are restricted inside phloem cells (Christensen et al. 2004; Weintraub and Beanland 2006). Phytoplasmas are small (less than $1 \mu \mathrm{m})$ and have very small genomes, averaging approximately $750 \mathrm{~kb}$, which may have resulted from genome reductions from their gram-positive ancestor (Hogenhout et al. 2008). As yet, in vitro culture of phytoplasmas is not possible; therefore, their detection and classification largely rely on molecular biology-based methods (Bertaccini and Duduk 2009).

Phytoplasmas cause various symptoms, including yellowing, stunting, proliferation, early bolting, phloem necrosis, witches'broom (clustering of multiple braches), and floral abnormalities such as discoloration, sterility, virescence (green coloration on non-green flower parts), and phyllody (floral organs becoming leaf-like) (Bertaccini 2007; Hogenhout et al. 2008). Because phytoplasma infection causes such strong perturbations in plant development, and phytohormones have important roles in plant development, it was proposed that the development disorders are due to hormonal imbalance (Tan and Whitlow 2001). Certainly, markedly increased cytokinin levels were detected in phytoplasma-infected virescent periwinkle flowers while the levels were reduced in infected leaves and roots (Davey et al. 1981). On the other hand, in vitro cultured periwinkle shoots infected with phytoplasma required much more exogenous auxin to induce roots (Chang, 1998). This finding implicates a defect in auxin response in phytoplasma-infected plants. Recently, a unique virulence factor from onion yellows phytoplasma was found to induce proliferation and dwarfism symptoms and suppress transcript abundance of a group of auxin-related genes (Hoshi et al. 2009). The finding strongly supports the involvement of hormonal imbalance in phytoplasma-induced developmental disorders. However, following aster yellows (AY) phytoplasma infection, typical virescence and phyllody symptoms were still observed in Arabidopsis thaliana mutants insensitive to auxin, gibberellin, abscissic acid, and ethylene (Lee et al. 2000). It is possible that the hormonal imbalance may only explain some but not all of the developmental disorders caused by phytoplasma infection.

Phytoplasma is by far the only bacteria found to cause these floral malformations. It is still not clear how and why phytoplasmas cause these symptoms. These malformations are clearly a series of floral reversion events, a return to vegetative growth after a period of floral development. Floral reversion does not 
happen often naturally; however, it can be induced by mutations and environmental changes (Tooke et al. 2005). For example, in Arabidopsis, floral reversion is frequently found in heterozygous lfy- 6 and homozygous ag- 1 mutants grown under a short-day condition (Okamuro et al. 1996). LEAFY (LFY) has a central role in promoting the transition from inflorescence shoot meristem development to floral meristem development (Moyroud et al. 2010). It acts to promote expression of its downstream floral organ identity genes (Parcy et al. 1998). AGAMOUS (AG), a MADS-box C-function gene that specifies stamen and carpel formation, controls the terminal growth of a flower through repression of WUSCHEL (WUS), an apical meristem maintaining gene (Krizek and Fletcher 2005). In Impatiens balsamina, unlike Arabidopsis, floral reversion occurs naturally when plants are transferred from a short day (a floral-inductive condition) to a long day (not a floral-inductive condition) (Battey and Lyndon 1984). In addition, Impatiens orthologs of $L F Y$ and $A G$ do not seem to be involved in determination of floral reversion because their transcript abundance does not correlated with the reversion (Ordidge et al. 2005; Pouteau et al. 1997). Mutations or gene silencing of SEPALLATA (SEP) genes also resulted in floral reversion in petunia, Arabidopsis, gerbera, and tomato (Ampomah-Dwamena et al. 2002; Angenent et al. 1994; Pelaz et al. 2000; Teeri et al. 2006). In these cases, petals and stamens were converted into green sepalloid organs, and new inflorescences were developed from flowers.

Floral abnormalities of phytoplasma-infected plants have also been studied by examining changes in transcript abundance of floral development genes. For example, floral development genes are deregulated in tomato infected with stolbur (STOL) phytoplasma (Pracros et al. 2006). Transcript abundance of a tomato LFY ortholog, FALSIFLORA (FA), increased and transcript abundance of an $A G$ ortholog, $T A G 1$, was only slightly affected in infected plants, indicating that, similar to floral reversion regulation in Impatiens spp., FA and TAG1 may not be the main factors in STOL phytoplasma-induced floral reversion in tomato. In hydrangea infected with Japanese hydrangea phyllody (JHP) phytoplasma, phyllody was associated with reduced expression of B-function genes and C-function genes in inflorescences at early flower developmental stages (Kitamura et al. 2009). B- and C-function genes are functionally conserved to specify floral organ identities; however, a lack of $\mathrm{B}$ and $\mathrm{C}$ functions is not sufficient to abolish floral meristem development (Causier et al. 2010).

whorls of floral organs, especially for PLY phytoplasma-infected plants. Sepals remained unchanged even in severely malformed flowers (Fig. 2). The pistil of a normal periwinkle flower is composed of two fused carpels and the stigma has a round surface (Fig. 2A and K). By contrast, the pistils of PLY phytoplasma-infected periwinkle flowers contained two enlarged and partially divided carpels (Fig. 2B), suggesting that the fusion of carpels was not completed. Stamens of the flowers failed to produce pollen and, instead, the anthers were filled with sponge-like cells (Fig. 2B, C, I, and L). Pollen sacs in the stamens were shrunk and the filaments and connective regions became thicker (Fig. 2I and L). In some cases, the stamens became green and leaf-like (phyllody), and an ectopic shoot instead of the pistil grew out at the forth whorl (floral reversion) (Fig. 2D). In flowers of PnWB phytoplasma-infected plants, carpel fusion was also not completed and, often, leaflike structures were observed (Fig. 2E and F). In some cases, green ovule-like structures can still be observed on the walls of the leaf-like ovary but, in some of the more severe cases, the ovule-like structures became leaf-like (Fig. 2F). The pollen sacs were also shrunk; however, unlike pollens of PLY phytoplasma-infected flowers, the pollens of PnWB phytoplasmainfected flowers looked similar to the normal pollens (Fig.
In this study, we focused on finding new factors that contribute to phytoplasma-induced floral malformations. Flowers of periwinkle (Catharanthus roseus) infected with either periwinkle leaf yellowing (PLY) phytoplasma, a group 16SrI phytoplasma recently found in Taiwan, or peanut witches'-broom $(P n W B)$ phytoplasma, a group 16SrII phytoplasma that affects a wide range of host plants and causes witches'-broom disease in Australia, Ryukyu, and Taiwan, were compared for morphological changes, phytoplasma distributions, and expression levels of genes that potentially caused these changes because these two phytoplasmas cause different levels of floral abnormalities in periwinkle plants. In this study, we found a new candidate gene, $\mathrm{CrSEP3}$, to be important for phytoplasmainduced floral reversion in periwinkle. The severity of floral symptoms was also associated with the accumulation of phytoplasmas in malformed flowers and their nearby leaves. The potential routes of phytoplasma-induced floral malformations are discussed.

\section{RESULTS}

\section{PLY phytoplasma and PnWB phytoplasma induced different degrees of morphological changes in periwinkle flowers.}

Periwinkle plants started producing abnormal flowers 2 to 3 weeks after their graft inoculation with PLY phytoplasmainfected periwinkle shoots. Flowers at this time were smaller, discolored, or partially virescent (Fig. 1B to D). Five to six weeks later, the majority of flowers on infected plants were very small and completely green (Fig. 1E).

The symptom development was slower in PnWB phytoplasma-infected periwinkle plants. Abnormal flowers usually were observed 4 to 5 weeks after side grafting with PnWB phytoplasma-containing shoots. Flowers at this time showed partial or complete virescence (Fig. $1 \mathrm{~F}$ to $\mathrm{H}$ ), sometimes accompanied with enlarged short corolla tubes, known as big bud symptoms (Fig. 2F). At 6 to 8 weeks after their side grafting, phyllody symptoms were observed and many flowers underwent full floral reversion, in which ectopic shoots grew out flowers (Fig. 1I and J), and showed witches'-broom characteristics. Floral phyllotaxy often remained on the ectopic shoots at the early stage of the floral reversion (Fig. 1J).

It is clear that floral structure changes on phytoplasmainfected plants were mainly restricted within the inner three $2 \mathrm{M})$. At the later stages, all floral organs became green and leaf-like (phyllody), and floral pedicels were elongated (Fig. $2 \mathrm{G}$ and $\mathrm{J}$ ). The floral organ abnormalities in the inner three whorls occurred at the same time. The floral morphological changes of both phytoplasma-infected plants largely resembled floral organ conversions and floral reversion caused by gene silencing or mutations of the SEP genes in petunia (Angenent et al. 1994; Vandenbussche et al. 2003). Moreover, the perturbation of SEP functions in petunia caused floral abnormalities mainly in the inner three whorls. Therefore, we decided to see whether $S E P$ gene expression is repressed in phytoplasma-infected periwinkle flowers. In addition, we also examined whether there were changes in transcript abundance of floral pigmentation genes and floral B- and C-function genes because discoloration and floral organ conversions were the most readily identifiable floral symptoms in phytoplasma-infected periwinkle plants.

\section{Identification of potential phytoplasma-affected genes.}

Based on the morphological changes observed in the phytoplasma-infected flowers, we decided to check the association of these changes with expression levels of the anthocyanin biosynthesis genes chalcone synthase $(C H S)$, and chalcone isom- 
erase $(C H I)$, and with expression levels of the floral organ identity genes: floral B-function genes (DEFICENS $[D E F]$ ) and GLOBOSA [GLO]), floral C-function genes $(A G)$, and SEP genes. The CHS sequence (accession number AJ131813) was obtained by a sequence name search of GenBank. To identify other candidate genes, degenerate primers were designed based on the conserved domain sequences from published sequences (details can be found below). The identified $D E F$ ortholog, CrDEF1, is $86 \%$ identical to DEF of Antirrhinum majus at the amino acid level. The amino acid sequence encoded by the isolated periwinkle $G L O$ ortholog, CrGLO1, is 79 and $78 \%$ identical to PhGLO2 and PhGLO1 of petunia, respectively. The amino acid sequence encoded by the isolated $A G$ ortholog, CrAG1, is $80 \%$ identical to a Nicotiana tabacum AG ortholog, NAG1. The sequences of CrSEP3 and FBP2, a SEP3 ortholog of petunia, are $91 \%$ identical. The identified $\mathrm{CHI}$ homolog, $\mathrm{CrCHI}$, shows $74 \%$ identity to $\mathrm{CHI}$ of Ipomoea purpurea at the amino acid level. The CrCHI sequence also contains conserved amino acids in its potential active site (Fig. 1S). A phylogenetic analysis was also performed for all identified MADS-box transcription factors using the neighbor-joining method with 10,000 bootstrap values. Sequences of floral B- and C-function MADS-box proteins as well as SEP of Arabidopsis, snapdragon, petunia, and tomato were included in this analysis. This analysis showed that all identified MADSbox transcription factors were grouped into their expected clades with high confidence (Fig. 3).

Southern blot analysis showed that only one to two DNA fragments hybridized with $\mathrm{CrDEF}, \mathrm{CrGLO1}, \mathrm{CrSEP} 3, \mathrm{CrCHS}$, and $\mathrm{CrCHI}$ probes (Fig. 4). This indicates that the genes recognized by the probes are single-copy genes or part of a very small gene family in the periwinkle genome. In contrast, periwinkle genome contains multiple genes encoding $A G$ because more than two DNA fragments were detected with the CrAG1 probe when treated with different restriction enzymes.

\section{PLY and PnWB phytoplasmas affected} transcript abundance changes in floral organ identity genes and anthocyanin biosynthesis genes similarly.

The transcript abundance of the examined floral organ identity genes and anthocyanin biosynthesis genes was lower in phytoplasma-infected flowers than in healthy control flowers (Fig. 5). Among the genes examined, transcript abundance of CrSEP3 showed the most significant repression in both phyto- plasma-infected plants, with approximately $80 \%$ reduction at S3 of plants infected by either phytoplasma and $90 \%$ reduction at S4 of PnWB phytoplasma-infected plants (Fig. 5D). Transcript abundance of $C r D E F 1$ was also strongly downregulated and correlated well with symptom expression after infection with either of phytoplasmas (Fig. 5A). However, changes of transcript abundance of $\mathrm{CrGLO1}$ in plants infected with different phytoplasmas were slightly different (Fig. 5B). In PLY phytoplasma-infected plants, transcript abundance of $C r G L O 1$ was only moderately decreased throughout symptom development but the downregulation of the transcript was associated with symptom development in PnWB phytoplasma-infected plants (Fig. 5B). CrAGl also showed only moderate suppression in phytoplasma-infected plants at S3 (Fig. 5C). However, at symptom stages before $\mathrm{S} 2$, its transcript abundance in malformed flowers was lower when caused by PLY phytoplasma than when caused by PnWB phytoplasma (Fig. 5C). The downregulation of the anthocyanin biosynthesis genes also showed good correlation with the reduction of floral pigmentation in periwinkle plants infected with either phytoplasmas, especially CrCHS. CrCHI expression was only slightly repressed in PnWB phytoplasma-infected periwinkle plants (Fig. 5E and F).

\section{Phytoplasmas preferentially colonized malformed flowers and were associated with severity of floral symptoms.}

Distribution and multiplication of phytoplasmas in plants affect symptom expression (Christensen et al. 2004; Kuske and Kirkpatrick 1992). To understand whether phytoplasma accumulation is also associated with floral symptom expression in PLY phytoplasma- and PnWB phytoplasma-infected periwinkle plants, and also to understand whether there is any biological meaning for phytoplasma to induce floral reversion, we examined phytoplasma accumulation in malformed flowers and their closest leaves in various degrees of floral severities using quantitative real-time polymerase chain reaction (PCR). Indeed, floral symptom expression strongly correlated with phytoplasma distribution in which high phytoplasma concentrations were detected in locations showing severe floral symptoms, especially in PnWB phytoplasma-infected plants (Fig. 6B). Compared with PLY phytoplasma, PnWB phytoplasma also accumulated to a much higher level in periwinkle flowers and their surrounding leaves at the later symptom stages (Fig. 6). Interestingly, we found also that, for flowers and leaves, phytoplasmas preferentially colonized flowers whose symp-

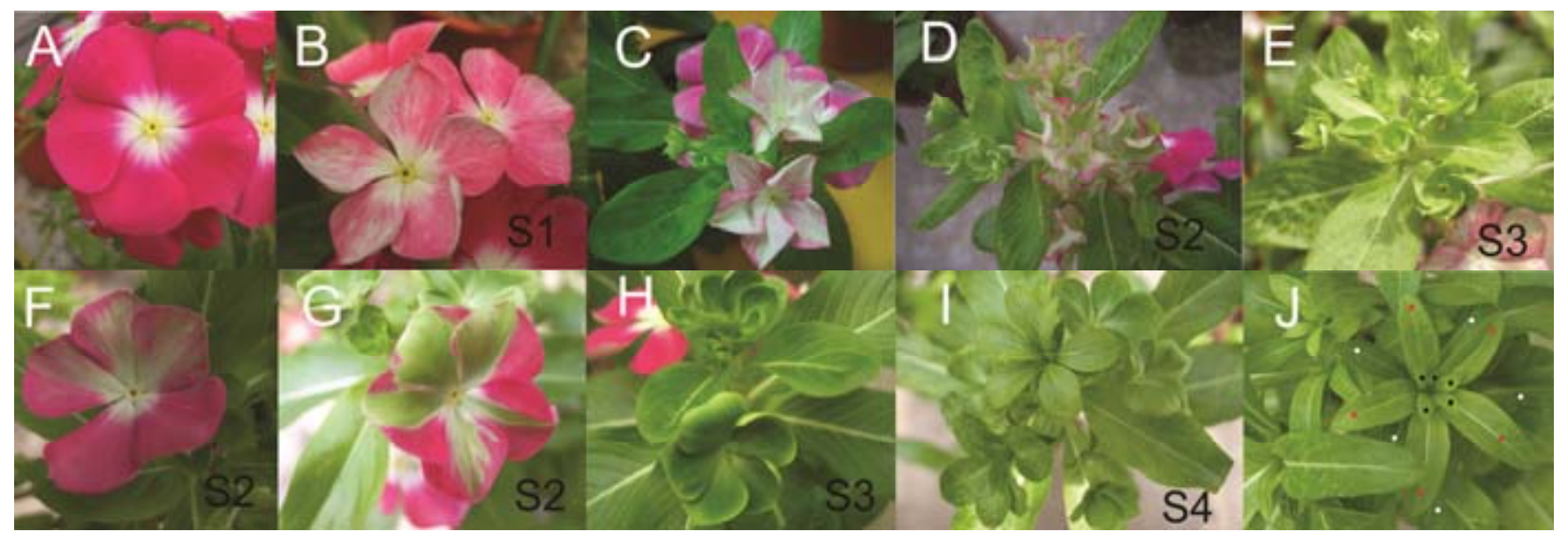

Fig. 1. Floral symptoms of periwinkle leaf yellowing (PLY) and peanut witches'-broom (PnWB) phytoplasma-infected periwinkle plants. A, Flowers of healthy periwinkle; B to E, flowers of PLY phytoplasma-infected periwinkle plants; and F to J, flowers of PnWB phytoplasma-infected periwinkle plants. Flowers exhibiting discoloration were defined as S1 symptom stage (B and C), flowers showing partial virescence are at the S2 stage (D, F, and G), flowers showing completed virescence are at the S3 stages (E and H), and phyllody flowers are at the stage S4 (I). Leaf-like floral organs in a malformed flower infected with PnWB phytoplasma are arranged the same as floral organs in a normal flower at the early witches'-broom stage (J). Dots in the same color indicate leaf-like organs in the same floral whorl $(\mathrm{J})$. 

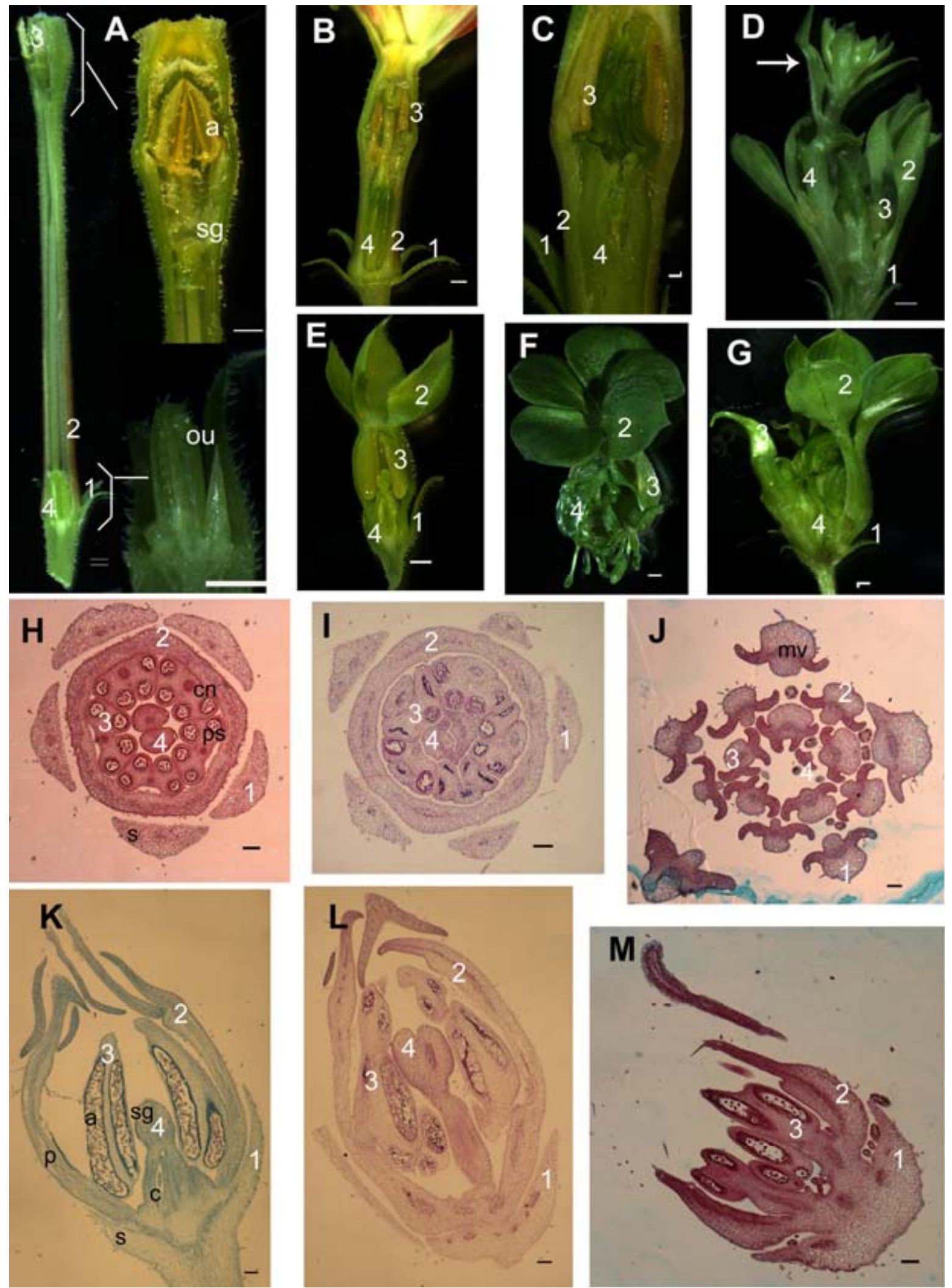

Fig. 2. Structural changes in flower organs of phytoplasma-infected periwinkle plants. A, H, and $\mathbf{K}$, Flowers of healthy periwinkle; B, C, D, I, and $\mathbf{L}$, flowers of periwinkle leaf yellowing (PLY) phytoplasma-infected periwinkle plants; and E, F, G, J, and M, flowers of peanut witches'-broom (PnWB) phytoplasma-infected periwinkle plants. $\mathbf{H}$ to $\mathbf{J}$, Longitudinal and $\mathbf{K}$ to $\mathbf{M}$, vertical sections of periwinkle flowers. The healthy flower contains a long corolla tube, a long style, an intact stigma with round surface, plump anthers containing mature pollens, and two carpels filled with round ovules (A). Flowers of phytoplasma-infected plants show malformations in all organs of inner three whorls, including shorter corolla tubes and green petals in the second whorl, shirked or leaf-like anthers in the third whorl, and shorter styles and swollen ovary in the fourth whorl (B, C, E, F, and G). An ectopic shoot instead of a pistil is found at the fourth whorl of PLY phytoplasma-infected periwinkle (D). The arrow points to the ectopic shoot with a newly formed flower. At the later stage of PnWB-infected flowers, all of the floral organs display leaf-like structures where midveins of the structures extend into lateral blade-like structures; however, the arrangement of these organs remain the same as that in a flower (J). Floral whorls are indicated. In healthy flower, the four whorls are sepal (1), petals (2), stamen (3), and carpels (4). Abbreviations: a = anther; $\mathrm{c}=$ carpel; $\mathrm{cn}=$ connective; $\mathrm{mv}=$ midvein; ou = ovule; $\mathrm{p}=$ petal; $\mathrm{ps}=$ pollen sac; $\mathrm{s}=$ sepal; $\mathrm{sg}=$ stigma; st $=$ stamen. Scale bar: $0.1 \mathrm{~cm}$. 
tom severity was over S2 (Fig. 6). In PnWB phytoplasmainfected plants, phytoplasma was barely detected in flowers showing no symptoms ( $\mathrm{S} 0$ stage) whereas phytoplasma at 2.55 genome units per picogram of plant DNA was detected in closest leaves. However, when virescence symptoms appeared, much higher phytoplasma concentrations were detected in malformed flowers. Similar results were also obtained in PLY phytoplasma-infected plants, in which phytoplasma concentrations showed no significant differences between malformed flowers and nearby leaves at S1 but higher concentrations were detected in malformed flowers at S2 and S3.

\section{DISCUSSION}

Many plant pathogens can alter host developmental processes for their benefit to enable successful colonization. For example, galls or tumors can be induced by bacterial pathogens such as Agrobacterium tumefaciens, Pseudomonas syringae, and Erwinia herbicola to provide required nutrients for the pathogens (Jameson 2000). In addition, developmental abnormalities, including stunting, leaf curling, and loss of apical dominance, are common symptoms associated with viral diseases of plants (Culver and Padmanabhan 2007). Strikingly,

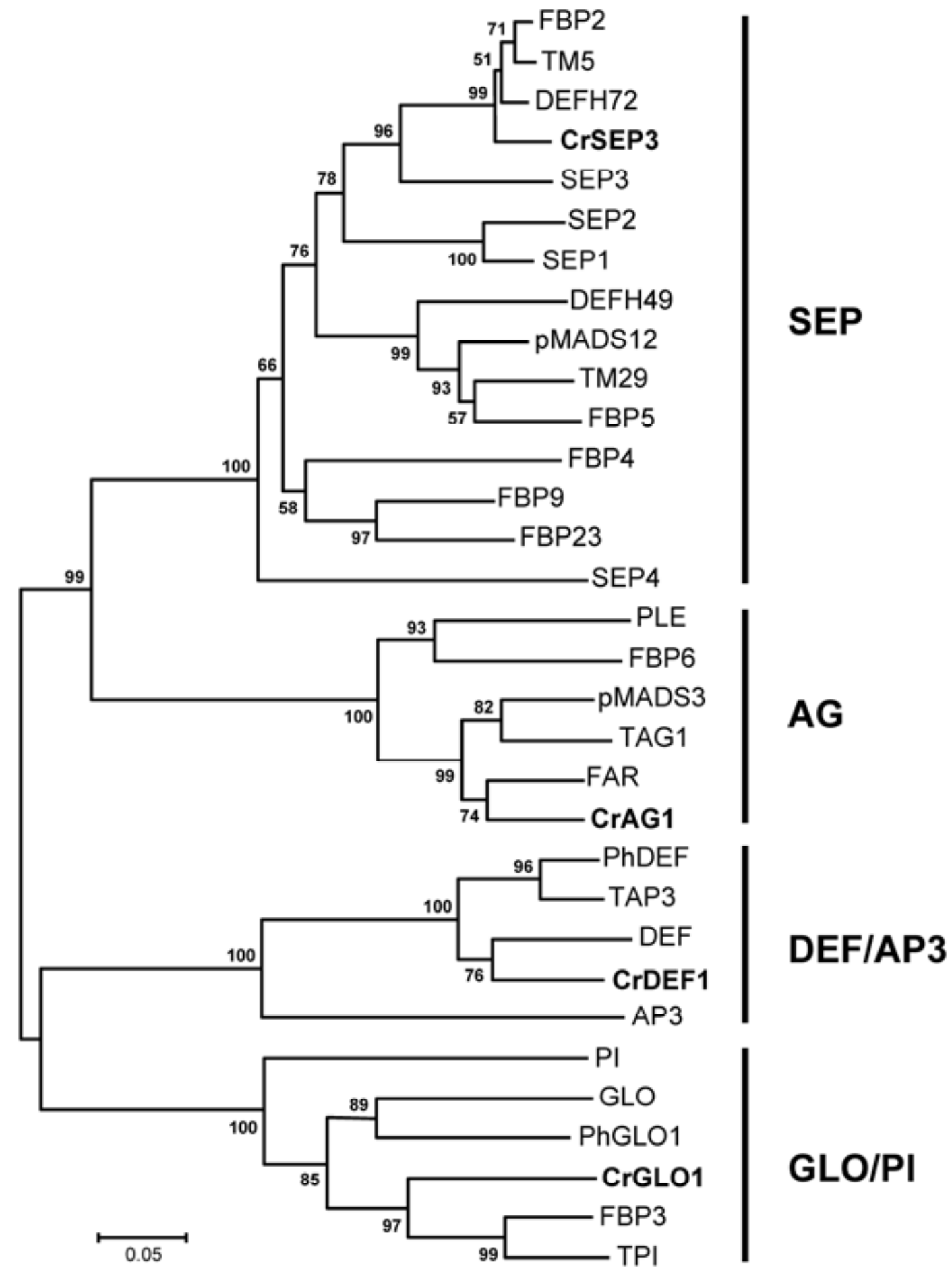

Fig. 3. Phylogenetic tree of selected members of MADS box transcription factors. Members of SEPALLATA (SEP), AGAMOUS (AG), DEFICENS (DEF)/ AP3 and GLOBOSA (GLO)/PI subgroups from Arabidopsis, snapdragon, tomato, and petunia were included in the analysis. Sequences from periwinkle are in bold. Bootstrap values are also indicated. 
virus-vector mutualism helps population increase of both the virus and the vector (Jiu et al. 2007; Yang et al. 2008). Tomato yellow leaf curl China virus (TYLCCNV) causes a leaf curling symptom and suppresses plant defense for its insect vector, type B whiteflies, to help accelerate propagation of the insect vector (Yang et al. 2008). Ectopic expression of $\beta C 1$, an RNAsilencing suppressor of TYLCCNV, in Arabidopsis resulted in abnormal leaf phenotype, including curled leaves and outgrowth tissues from abaxial leaves, which resembles viral symptoms caused by TYLCCNV. The phenotypical changes caused by $\beta C 1$ were due to its interaction with ASYMMETRIC LEAVES 1 (AS1), a key leaf development regulator (Yang et al. 2008).

Phytoplasmas are the only bacteria known to cause floral reversion. Spiroplasma citri is another phloem-restricted bacterial pathogen. However, it does not cause flower abnormalities on its hosts. The exact mechanism that causes floral symptom development is still unclear, and whether this symptom

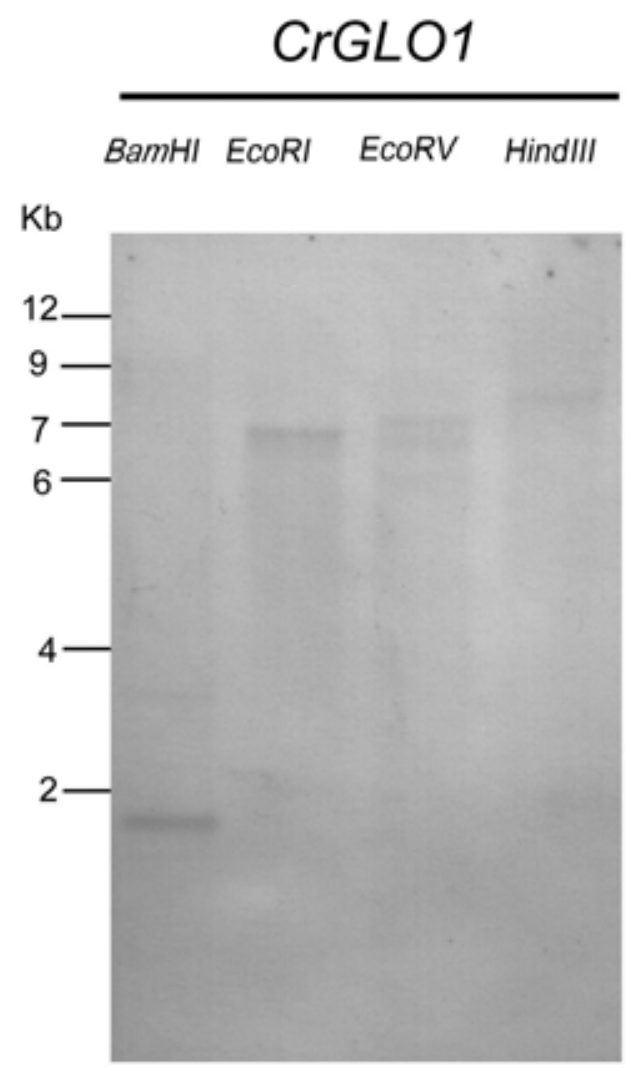

CrSEP3

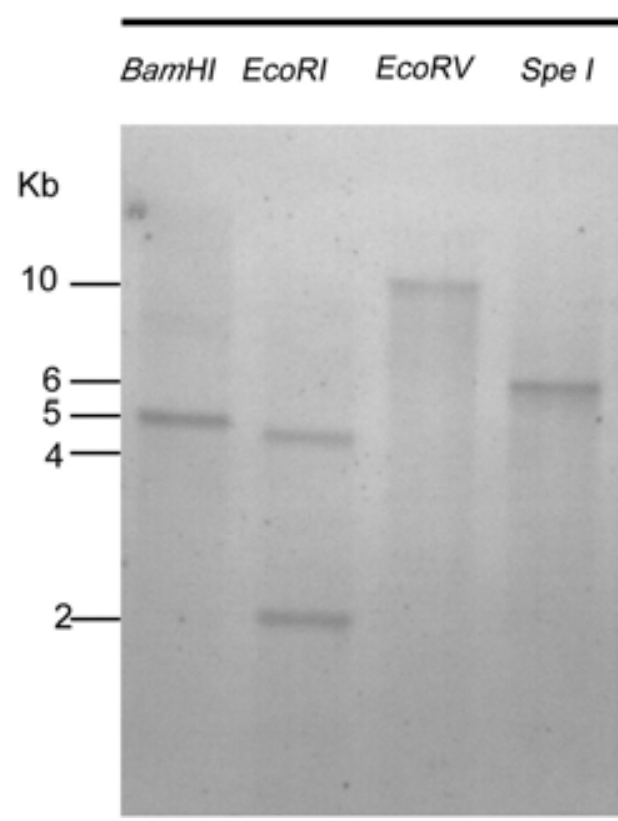

CrAG1
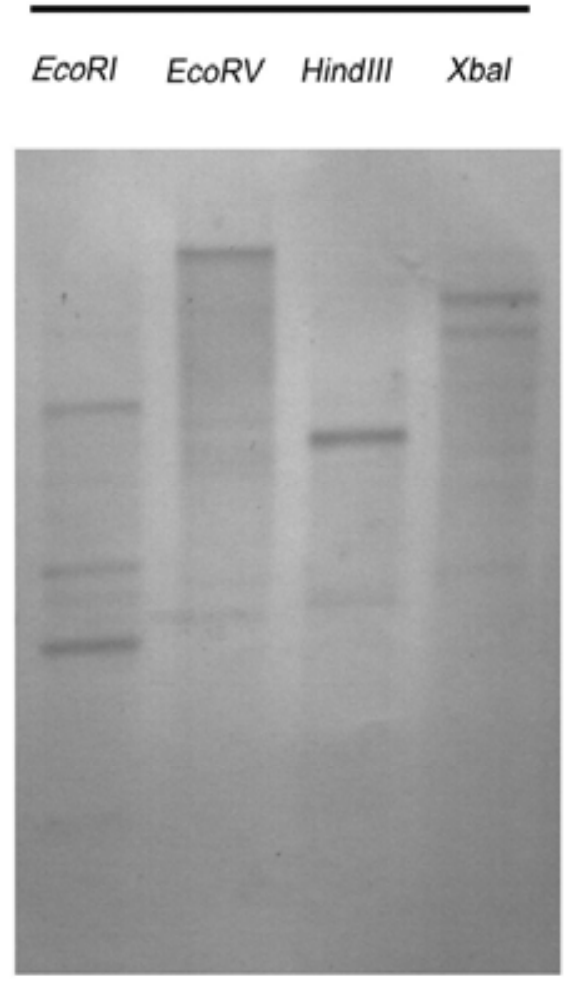

$\mathrm{CrCHS}$

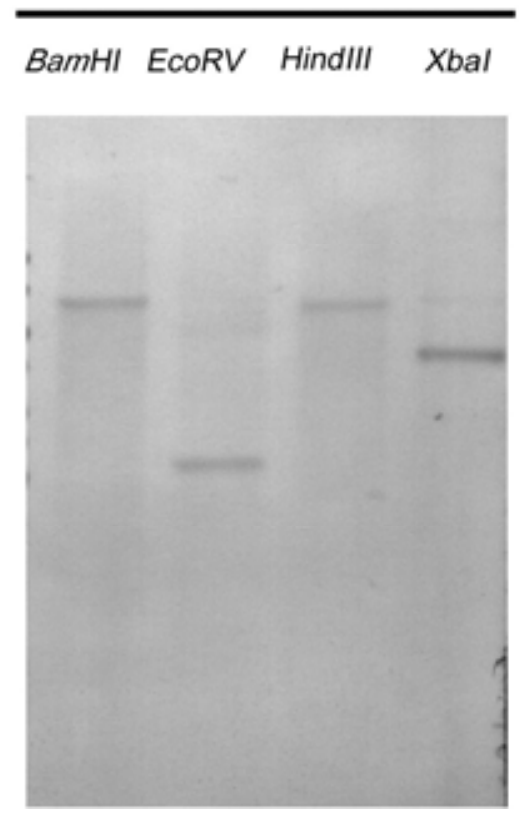

$\mathrm{CrCHI}$

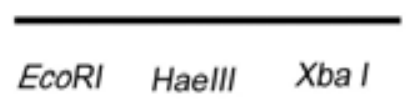

\section{CrDEF1}

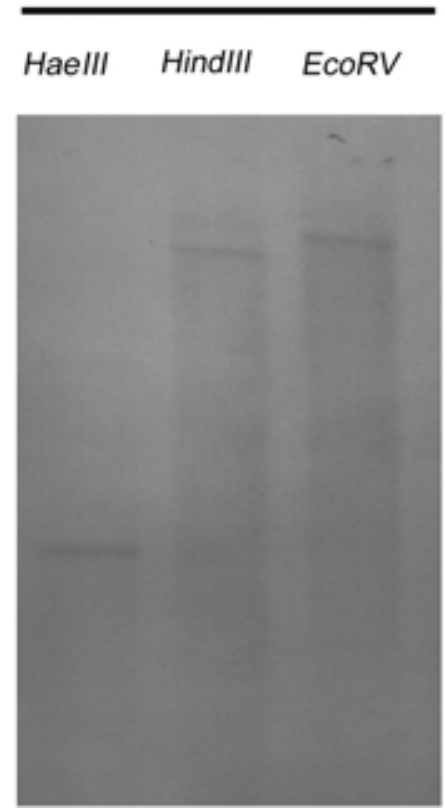

Fig. 4. Southern blot analysis of periwinkle genomic DNA. Genomic DNA was digested with different restriction enzymes indicated and membranes were hybridized with cDNA fragments containing conserved regions of each listed gene. 
development is necessary for successful colonization of phytoplasmas is also poorly understood. This information may help us to develop new strategies to prevent plants from phytoplasma infection. Pracros and associates (2006) documented that several floral developmental genes were deregulated in STOL phytoplasma-infected tomato flowers, in which an inflorescence identity gene, $F A$, was upregulated; in contrast, apical meristem maintenance genes LeWUSCHEL (LeWUS) and LeCLAVATA1 (LeCLVI) and a floral B-function gene, LeDEFICIENS (LeDEF), were downregulated. Similarly, in JHP phytoplasma-infected hydrangea, B- and C-function genes were downregulated (Kitamura et al. 2009). Though the deregulation of these floral developmental genes demonstrates a reprogrammed developmental process in malformed flowers, the findings may not be sufficient to explain the floral reversion because, in Arabidopsis, floral reversion can be induced when functions of LFY and AG are lost; however, transcript abundance of $F A$ was upregulated and transcript abundance of $\mathrm{AG}$ changed only slightly in STOL phytoplasma-infected tomato. In addition, loss of $\mathrm{B}$ and $\mathrm{C}$ functions in Arabidopsis did not result in floral reversion. These genes have not been examined in different stages of the symptom development. Therefore, we tried to identify new factors that contribute to the process and examine their expression levels in different symptom expressions. PLY phytoplasma and PnWB phytoplasma induced different degrees of floral reversion in infected periwinkle plants. PLY phytoplasma caused discoloration, virescence, small flowers, and phyllody in periwinkle flowers but rarely induced completed floral reversion (Fig. 1). In contrast, floral symptoms were more severe in PnWB phytoplasma-infected periwinkle plants. Flowers of these plants often underwent complete floral reversion and exhibited witches'-broom symptoms at later stages (Fig. 1). However, the floral reversions caused by both phytoplasmas largely resembled the phenotypes of mutants or gene silencing of SEP genes in petunia (Angenent et al. 1994; Vandenbussche et al. 2003).
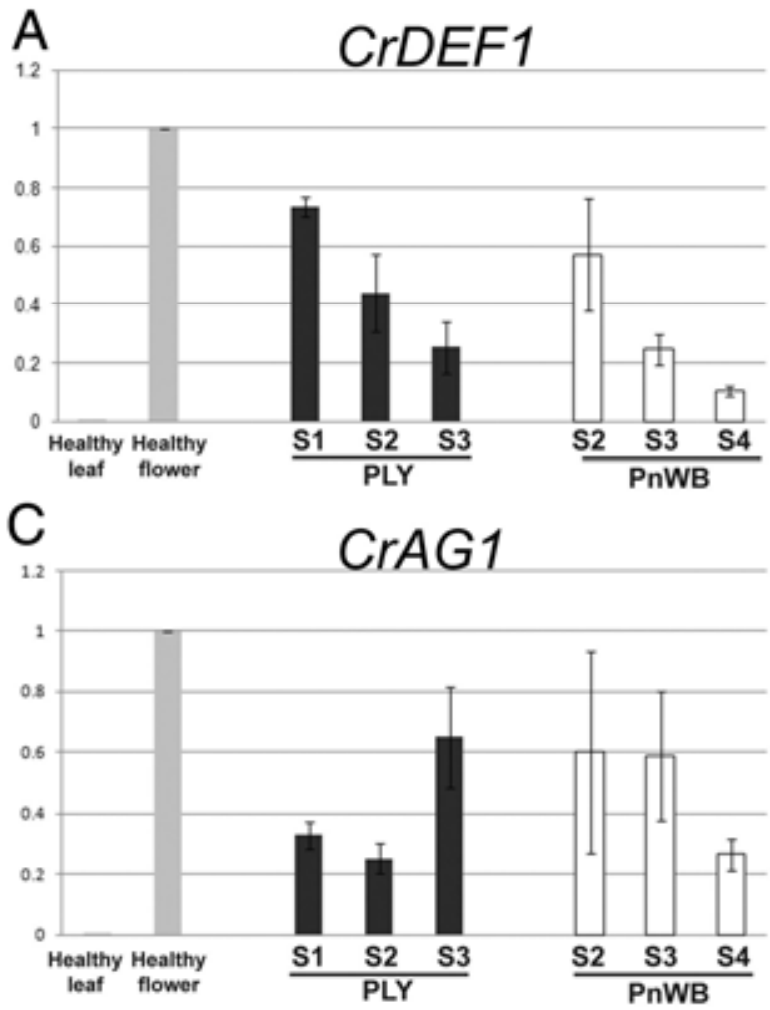

B
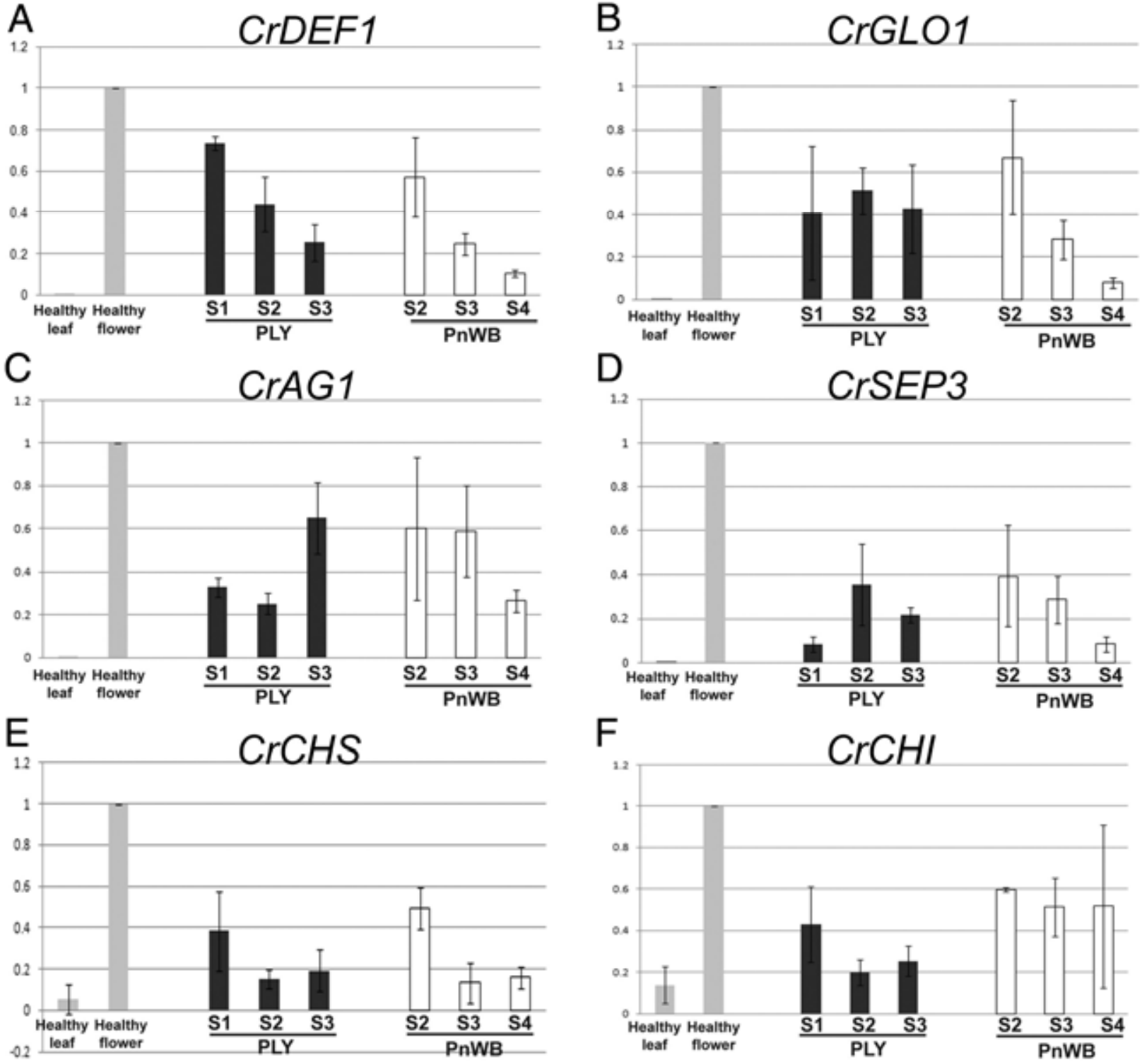

Fig. 5. Relative gene expression levels of floral organ identity genes and pigmentation genes in different floral symptom stages of phytoplasma-infected periwinkle. Flowers from periwinkle leaf yellowing phytoplasma-infected periwinkle plants are shown in black and from peanut witches'-broom phytoplasmainfected periwinkle plants are shown in white. Gene expression levels of healthy periwinkle flower are indicated as 1 . Gene expression levels of healthy periwinkle leaves were also analyzed to be a control. Three classes of floral organ identity genes analyzed are B-function genes $\mathbf{A}, D E F I C E N S$ ( $D E F) 1$ and $\mathbf{B}$, GLOBOSA (GLO)1; C, C-function gene AGAMOUS (AG); and D, SEPALLATA-like gene SEP3. Two pigmentation genes analyzed are E, chalcone synthase $(C H S)$ and $\mathbf{F}$, chalcone isomerase $(C H I)$. Results were from three biological repeats. 
SEP proteins are required for proper $\mathrm{B}$ and $\mathrm{C}$ functions in floral organ identity determination (Malcomber and Kellogg 2005; Pelaz et al. 2000). Studies on Arabidopsis have also revealed that SEP3 interacts with APETALA1 (AP1) and works also with LFY to promote floral meristem development (Liu et al. 2009; Pelaz et al. 2001). Recently, SEP3 was found to directly drive expression of B- and C-function genes though other factors are required to work with SEP3 in the activation (Kaufmann et al. 2009). Amazingly, constitutive expression of SEP3 and LFY in Arabidopsis is sufficient to ectopically trigger floral organ formation (petals, carpels, and ovules) outside of the floral context (Castillejo et al. 2005). Therefore, SEP proteins are not only important for floral organ identity but also required for floral meristem identity. Therefore, we hypothesized that the loss of SEP functions may be important in phytoplasma-induced floral malformations. Indeed, CrSEP3 expression levels were strongly suppressed in both phytoplasma-infected periwinkle plants (Fig. 5D). The results from our examination on B- and $\mathrm{C}$-function genes were generally consistent with the previous findings in STOL phytoplasma-infected tomato (Fig. 5A to C) (Pracros et al. 2006). However, differences in expression profiles of $\mathrm{CrGLO1}$ and $\mathrm{CrAGl}$ between floral symptom developments of these two phytoplasma-infected plants can still be seen. The differences may explain the stronger defect on anther development in early symptom stages caused by PLY phytoplasma because B- and C-function genes are both important for stamen development (Fig. 2B, E, L, and M). Expression profiles of anthocyanin biosynthesis genes during floral symptom development were similar in plants infected with either of the two phytoplasmas (Fig. 5E and F). Our results also indicate that $\mathrm{CrCHS}$ may have a role in the discoloration symptom in phytoplasma-infected plants.

Symptom expression and phytoplasma concentrations in plants infected with either of phytoplasmas showed a strong correlation (Fig. 6). AY phytoplasma concentrations were also correlated with symptom expressions in aerial parts of phytoplasma-infected periwinkle plants (Kuske and Kirkpatrick 1992). It is not clear how a phloem-restricted pathogen can interfere with floral meristem development. The recent finding on a phytoplasma virulence factor, TENGU, suggests that secreted proteins from phytoplasma may travel into apical meristem and influence plant developmental processes (Hoshi et al. 2009). It is possible that an as-yet-unknown factor is secreted from phytoplasma and acts in the floral meristem to suppress expression of floral meristem identity genes, such as CrSEP3, resulting in floral malformations. It is also possible that high concentrations of phytoplasma block transport of flowering signals inside the phloem. Studies on floral reversion revealed the importance for a leaf-derived signal to maintain floral commitment, and that the signal is very likely to be transported through phloem (Corbesier et al. 2007; Michaels 2009; Tooke et al. 2005). Leaf removal of periwinkle plants also led to production of slightly green flowers (J. C. Chen, unpublished results). In both cases, severities of floral symptoms are likely the consequence of the accumulation of phytoplasmas.

Interestingly, we found that phytoplasmas were able to accumulate to higher levels in flowers than those in surrounding leaves after floral symptom development into the $\mathrm{S} 2$ stage but not before the S2 stages (Fig. 6). High phytoplasma levels were also found in flowers of periwinkle infected with ' $C a n d i-$ datus Phytoplasma australiense'. The flowers instead of midribs were used to isolate phytoplasma DNA because flowers were the best source for the DNA isolation (Tran-Nguyen et al. 2008). However, it was suggested that phytoplasmas colonize poorly in floral organs (Pracros et al. 2006). It was proposed that phytoplasmas induce morphological changes in plants to increase their chances for their transmission by insect vectors (Hoshi et al. 2009). Because many plant pathogens can alter developmental processes of their hosts for successful accumulation, it is intriguing to find out whether phytoplasmas will have a similar approach. Though the direct evidence that phytoplasmas induce floral malformations to increase their population is still lacking, our findings may point to the possibility. Alternatively, the higher phytoplasma concentrations in malformed flowers may have been due to a high nutrient accumulation at the actively growing sites. Further studies will be needed to unravel the mechanisms. It is known that the floral symptoms are not observed in all phytoplasma-infected hosts, and symptom development is dependent on phytoplasma strains and host plants (Seemuller and Schneider 2007). To further dissect the role of the floral malformations for phytoplasmas, it will be interesting to see whether interference on floral symptom development will affect phytoplasma accumulation. Comparisons of transmission potential between strains that induce floral malformation and strains that do not induce it will also help us understand the importance of the unique symptom.
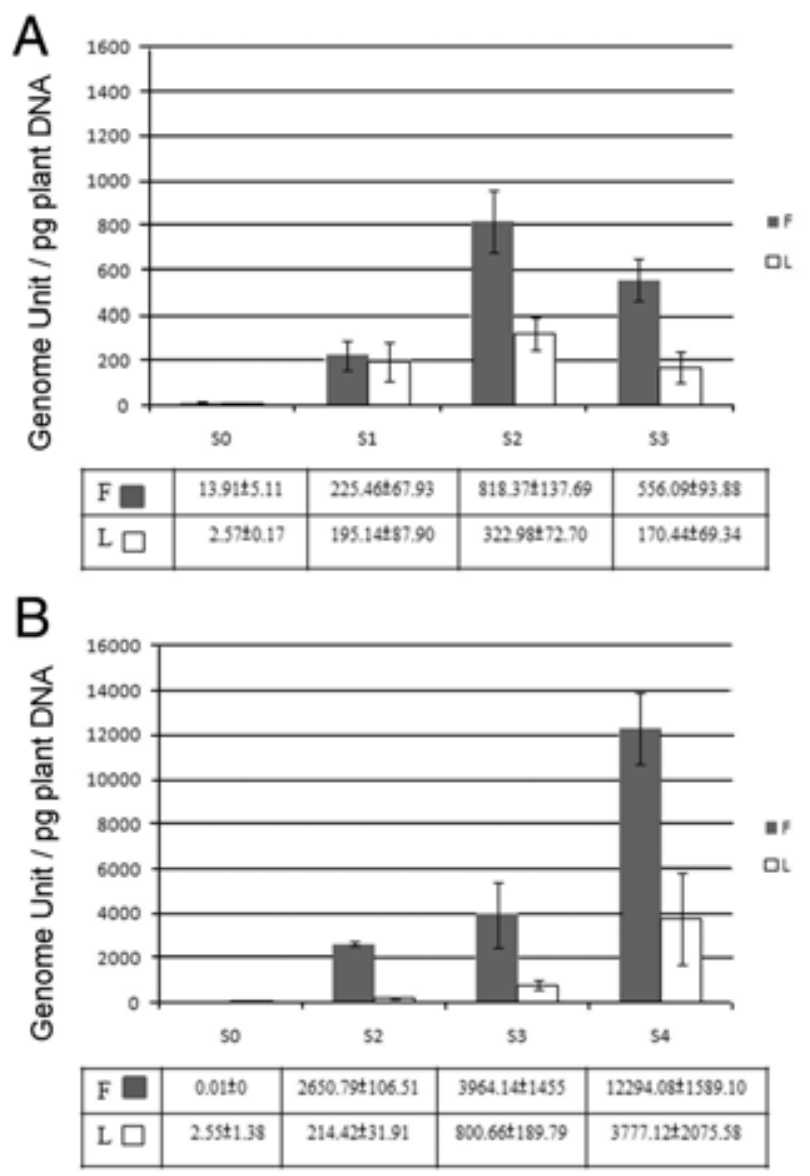

Fig. 6. Phytoplasma accumulation in periwinkle leaf yellowing (PLY) phytoplasma- or peanut witches'-broom (PnWB) phytoplasma-infected periwinkle plants. A, Phytoplasma levels of PLY phytoplasma-infected plants at different floral symptom stages. B, Phytoplasma levels of PnWB phytoplasma-infected plants at different floral symptom stages. Gray bars indicate phytoplasma levels in flowers and white bars indicate the levels in leaves. Malformed flowers and their closest bract leaves were analyzed. S0 indicates the flowers did not show visible symptoms. Data are indicated by means of three sample replications. The three floral symptom stages for PLY phytoplasma-infected plants are S1 (discoloration), S2 (partial virescene), and S3 (completely virescence), and for PnWB phytoplasmainfected plants, the three stages are S2, S3, and S4 (phyllody). The table below shows the phytoplasma levels (phytoplasma genomic units per picogram of plant DNA \pm standard deviation) at the stages indicated above. 


\section{MATERIALS AND METHODS}

Materials and culture conditions.

PLY phytoplasma was originally obtained from Taoyuan County, Taiwan, in 2005. PnWB phytoplasma was a gift from I. L. Yang, Taiwan Agricultural Research Institute, Wufeng, Taiwan. Phytoplasmas were maintained and propagated in periwinkle plants (C. roseus 'Pacifica Punch Halo') by serial transmissions by side grafting using 4-month-old plants. The plants were maintained in a greenhouse condition. Flower symptoms were classified into four stages according to symptom severity. The four symptom stages were S1 (discoloration of petals), S2 (partial virescence of petals), S3 (complete floral virescence), and S4 (complete phyllody) (Fig. 1). For each phytoplasma study, nine plants were used, in which three plants were counted as one unit, and samples of flowers and leaves of all stages collected from the same unit were one biological repeat. Flower and leaf samples were separated into two for RNA and DNA extraction to quantify transcript abundance of candidate genes and phytoplasma concentrations, respectively. For experiments on PLY phytoplasmas, samples were collected 3 weeks after graft inoculations and, for experiments on PnWB phytoplasmas, samples were collected 4 weeks after graft-inoculations. All samples were collected within 10 days.

\section{Histological analysis.}

The histological analysis was performed as described previously with slight modification (Johansen 1990). Floral buds were fixed in FAA solution (3.7\% formaldehyde, 5\% acetic acid, and $50 \%$ ethanol), and dehydrated through an alcohol/xylene substitute series. After dehydration, samples were embedded in paraffin. The embedded tissues were sectioned to $8 \mu \mathrm{m}$ with microtome and stained with safranin O/Fast Green solution.

\section{RNA isolation and cDNA synthesis.}

Approximately $0.2 \mathrm{~g}$ of each sample was used for total RNA extraction using the TRIzol reagent (Invitrogen Corporation, Carlsbad, CA, U.S.A.) according to the manufacturer's instructions and treated with TURBO DNase (Applied Biosystems, Foster City, CA, U.S.A.) to remove residual DNA. First-strand cDNA was synthesized using $2 \mu \mathrm{g}$ of DNase-treated total RNA, oligo d(T) primer, and Superscripts III reverse transcriptase (Invitrogen Corporation).

Table 1. Primers used in this study

\begin{tabular}{|c|c|c|c|}
\hline Primer & Sequence $\left(5^{\prime} \text { to } 3^{\prime}\right)^{a}$ & Target sequence $^{\mathrm{b}}$ & Purpose $^{\mathrm{c}}$ \\
\hline CrPI-F & ATG GGG AGA GGA AAG ATT GA & $P I$ & Gene cloning \\
\hline CrPI-R & TTG TTG ATG CCA GAA ATA CGG & PI & Gene cloning \\
\hline $\mathrm{CrAP} 3-\mathrm{F}^{\mathrm{d}}$ & GAT YSA GAT CAA GAG G & AP3 & Gene cloning \\
\hline CrAP3-R ${ }^{\mathrm{d}}$ & RYC CAT ART GHG GAT C & AP3 & Gene cloning \\
\hline $\mathrm{CrAG}-\mathrm{F}^{\mathrm{d}}$ & GGR AGR GGR AAG ATY GAR AT & $A G$ & Gene cloning \\
\hline CrAG-R ${ }^{\mathrm{d}}$ & TCA CCC AKC AWK TKY CTG TT & $A G$ & Gene cloning \\
\hline CrSEP3-F ${ }^{\mathrm{d}}$ & TTY GCW AAR MGA AGR AAT GR & SEP3 & Gene cloning \\
\hline CrSEP3-R ${ }^{\mathrm{d}}$ & TGW AGW RTK GGT TCA CAT TC & SEP3 & Gene cloning \\
\hline CrCHS-F & CGC CGT CGA ATT GTG TTG ACC A & CHS & Gene cloning \\
\hline CrCHS-R & TCC ACA GTA AGA CCC GGT CCA AA & CHS & Gene cloning \\
\hline $\mathrm{CrCHI}_{-} \mathrm{F}^{\mathrm{d}}$ & TTC RTV AAR TTC ACS GGV AT & $\mathrm{CHI}$ & Gene cloning \\
\hline CrCHI-R ${ }^{d}$ & GCC AAA CTY TKY TTT GCW GCA G & $\mathrm{CHI}$ & Gene cloning \\
\hline $\mathrm{CrAP} 3 \mathrm{pF}$ & GAT CCA GAT CAA GAG G & $A P 3$ & Southern probe \\
\hline $\mathrm{CrAP} 3 \mathrm{pR}$ & GTC CAT AGT GTG GAT C & $A P 3$ & Southern probe \\
\hline $\mathrm{CHSpF}$ & CTG TTC AGA AAT CAC CGC CGT CGT CAC & CHS & Southern probe \\
\hline CHSpR & GAA GCA CCA CAG TCT CCA CAG TAA & CHS & Southern probe \\
\hline PIpF & GGG ATA ATG AAG AAG GC & $P I$ & Southern probe \\
\hline PIpR & ATG CCC TCA ATT CAC TG & PI & Southern probe \\
\hline $\mathrm{AGpF}$ & GGC GGA ACG GAT TAT TGA & $A G$ & Southern probe \\
\hline $\mathrm{AGpR}$ & CAT TTG ATT GAA GTC CAT TTA C & $A G$ & Southern probe \\
\hline CHIpF & TCA TGA AGT TCA CGG G & $\mathrm{CHI}$ & Southern probe \\
\hline CHIpR & TTG CAG CAG GTG ATA C & $\mathrm{CHI}$ & Southern probe \\
\hline $\mathrm{SEP} 3 \mathrm{pF}$ & GCC CTT TTC GCA AAG AGA AGG & SEP3 & Southern probe \\
\hline SEP3pR & TGA GAG CAA AAG CAT GCC AGG & SEP3 & Southern probe \\
\hline PnWB-impR & TGA AGA AAA TAA CAA AGC AGA CAT T & imp & Real-time PCR \\
\hline PnWB-impF & CAA TTA GTA ACA CTA GCG TTC TCA TTA ACA & imp & Real-time PCR \\
\hline PLY-amprtF & TGT AAA AGT AGC GGT TGC TGA TAA TAA & amp & Real-time PCR \\
\hline PLY-amprtR & CGC CTA CTA AAC TTA ATA CTT TTG AAC CT & amp & Real-time PCR \\
\hline UBQ-1252F & GCT GCT CTG GTG ATT GAT GGT & Ubiquitin & Real-time PCR \\
\hline UBQ-1392R & CCA AAA GGA ACC CGA AAA CA & Ubiquitin & Real-time PCR \\
\hline $\mathrm{AP} 3 \mathrm{rtF}$ & CAG TGC CAT TAG AGA GAG GAA GAA GTT T & $A P 3$ & Real-time PCR \\
\hline AP3rtR & CTG TGT ATT TCT TCA ACA TTT CTT ACC TTT & AP3 & Real-time PCR \\
\hline PIrtF & GGT TAG AGA TTA CCA ATC CCA GAT G & $P I$ & Real-time PCR \\
\hline PIrtR & TCC TCT CGT GCA GAT TTG GTT & PI & Real-time PCR \\
\hline AGrtF & AGC TGA AAC AGA AAG GGC ACA T & $A G$ & Real-time PCR \\
\hline AGrtR & CCG GGA AGA TCC TTG AGT AAA T & $A G$ & Real-time PCR \\
\hline SEP3rtF & TGG CTT CTT TCA TCC TTT GGA & SEP3 & Real-time PCR \\
\hline SEP3rtR & TGC TGC AAC TGT TAT TGG ATC AT & SEP3 & Real-time PCR \\
\hline $\mathrm{CHSrtF}$ & GCC ACG GCG CTA TCG AT & CHS & Real-time PCR \\
\hline CHSrtR & CCG GGA ACA TCC TTG AGT AAA T & CHS & Real-time PCR \\
\hline CHIrtF & CAC CTG GTG CCT CCA TTG TT & CHI & Real-time PCR \\
\hline CHIrtR & TTG GTG AAG CTG ATC GTT AAT GA & $\mathrm{CHI}$ & Real-time PCR \\
\hline
\end{tabular}


Identification and sequence analyses of candidate genes.

The candidate genes were cloned using degenerate oligonucleotide-primed PCR. The degenerate primers are listed in Table 1. The PCR products were column purified and cloned into pCRII-TOPO vector (Invitrogen Corporation) for sequencing. Rapid amplification of DNA ends PCR was used to extend the $3^{\prime}$ end sequence. The obtained candidate gene sequences were deposited into the GenBank, and the accession numbers are CrDEF1 (HQ343408), CrGLO1 (HQ343409), CrAGl (HQ343410), CrSEP3 (HQ343411), and CrCHI (HQ343412). To confirm the identity of each isolated candidate, a blastx was used to blast candidate sequences with the National Center for Biotechnology Information $\mathrm{nr}$ protein database. A phylogenetic analysis was also performed to confirm the lineage of floral developmental genes. Because chalcone isomerase genes are distinct from MADS box genes, it was not included in the phylogenetic analysis and, instead, a multiple sequence alignment was used to confirm its identity. The deduced amino acid sequences of candidate genes were used in a phylogenetic analysis using the MEGA program by neighbor-joining method with 10,000 bootstrap values indicated. B- and C-function protein as well as SEP-like protein sequences from Arabidopsis, snapdragon, petunia, and tomato were obtained from GenBank and included in this analysis. The accession numbers are: Arabidopsis thaliana sequences AG (NP_567569.3), PI (NP 197524.1), AP3 (NP_191002.1), SEP1 (NP_001119230.1), SEP2 (NP_186880.1), SEP3 (NP_850953.1), and SEP4 (NP 178466.1); snapdragon sequences DEF (CAA44629.1), GLO (CAA48725.1), PLE (BAI68391.1), FAR (CAB42988.1), DEFH72 (CAA64742.1), and DEFH49 (CAA64741.1); petunia sequences PhGLO1 (AAS46018.1), PhGLO2 (CAA50549.1), PhDEF (AAQ72510.2), FBP6 (CAA48635.1), pMADS3 (CAA51417.1), FBP2 (AAA86854.1), FBP4 (AAK21247.1), FBP5 (AAK21248.1), FBP9 (AAK21249.1), FBP23 (AAK21254.1), and pMADS12 (AAQ72498.1); and tomato sequences TM29 (CAC83066.1), TM5 (Q42464.1), TAG1 (AAA34197.1), TAP3 (ABG73412.1), and TPI (ABG73411.1).

\section{Southern-blot hybridization.}

Periwinkle DNA was extracted as described previously by Ko and Lin (1994). Genomic DNA (10 $\mu \mathrm{g}$ per lane) was digested with various restriction enzymes, separated in $0.8 \%$ agarose gel, transferred to a Hybond $\mathrm{N}+$ nylon membrane (Amersham Biosciences, Piscataway, NJ, U.S.A.), and hybridized with a cDNA probe of a candidate gene. The probes were labeled using a digoxigenin probe synthesis kit (Roche Molecular Biochemicals). cDNA fragments that cover conserved regions were used to synthesize the probes. Membranes were hybridized at $50^{\circ} \mathrm{C}$ and washed at $62^{\circ} \mathrm{C}$. The primers used for probe syntheses were listed on the Table 1.

\section{Quantitative reverse-transcription PCR.}

First-strand cDNA was used as template for real-time quantitative reverse-transcription (RT)-PCR. A SYBR Green (Applied Biosystems) method was used in an ABI Prism 7000 Sequence Detection System (Applied Biosystems). Ubiquitin was used as the reference gene for normalizing of transcript abundance. The primers used for quantitative RT-PCR were listed on the Table 1. Samples were tested in triplicate.

\section{Phytoplasma quantification.}

The phytoplasma quantification method was based on a previously described absolute quantification PCR method (Lee et al. 2008). Approximately $0.2 \mathrm{~g}$ of each sample was used for total DNA isolation to be the template using a DNeasy plant mini kit (Qiagen, Germantown, MD, U.S.A.), and primers designed to the immunodominant membrane protein gene and antigenic membrane protein gene were used to calculate PnWB and PLY phytoplasma concentrations, respectively. Periwinkle ubiquitin gene was used as internal control to normalize the cell numbers of phytoplasma in periwinkle. Primers designed for each target gene are listed on Table 1. The concentrations of phytoplasma were presented to be the phytoplasma copy number (genome unit/quantity [picograms]) of periwinkle DNA. Samples were tested in triplicate.

\section{ACKNOWLEDGMENTS}

This work was partly supported by the National Science Council, Taiwan (grant number 97-2313-B-002-022-MY3), and by National Taiwan University. We thank C.-N. Wang for his help on histological analyses and phylogenetic analyses, and for sharing his knowledge of flower development; and D. Hunter for his revision and kind comments on the manuscript.

\section{LITERATURE CITED}

Ampomah-Dwamena, C., Morris, B. A., Sutherland, P., Veit, B., and Yao, J. L. 2002. Down-regulation of TM29, a tomato SEPALLATA homolog, causes parthenocarpic fruit development and floral reversion. Plant Physiol. 130:605-617.

Angenent, G. C., Franken, J., Busscher, M., Weiss, D., and Vantunen, A. J. 1994. Co-suppression of the petunia homeotic gene Fbp2 affects the identity of the generative meristem. Plant J. 5:33-44.

Battey, N. H., and Lyndon, R. F. 1984. Changes in apical growth and phyllotaxis on flowering and reversion in Impatiens balsamina L. Ann. Bot. 54:553-567.

Bertaccini, A., 2007. Phytoplasmas: Diversity, taxonomy, and epidemiology. Front. Biosci. 12:673-689.

Bertaccini, A., and Duduk, B., 2009. Phytoplasma and phytoplasma diseases: A review of recent research. Phytopathol. Mediterr. 48:355-378.

Castillejo, C., Romera-Branchat, M., and Pelaz, S. 2005. A new role of the Arabidopsis SEPALLATA3 gene revealed by its constitutive expression. Plant J. 43:586-596.

Causier, B., Schwarz-Sommer, Z., and Davies, B., 2010. Floral organ identity: 20 years of ABCs. Semin. Cell Dev. Biol. 21:73-79.

Chang, C. J., 1998. Pathogenicity of aster yellows phytoplasma and Spiroplasma citri on periwinkle. Phytopathology 88:1347-1350.

Christensen, N. M., Nicolaisen, M., Hansen, M., and Schulz, A. 2004. Distribution of phytoplasmas in infected plants as revealed by real-time PCR and bioimaging. Mol. Plant-Microbe Interact. 17:1175-1184.

Corbesier, L., Vincent, C., and Jang, S. H. 2007. FT protein movement contributes to long-distance signaling in floral induction of Arabidopsis. Science 316:1030-1033.

Culver, J. N., and Padmanabhan, M. S. 2007. Virus-induced disease: Altering host physiology one interaction at a time. Annu. Rev. Phytopathol. 45:221-243.

Davey, J. E., Vanstaden, J., and Deleeuw, G. T. N. 1981. Endogenous cytokinin levels and development of flower virescence in Catharanthus roseus infected with mycoplasmas. Physiol. Plant Pathol. 19:193-200.

Hogenhout, S. A., Oshima, K., Ammar, E. D., Kakizawa, S., Kingdom, H. N., and Namba, S. 2008. Phytoplasmas: Bacteria that manipulate plants and insects. Mol. Plant Pathol. 9:403-423.

Hoshi, A., Oshima, K., and Kakizawa, S. 2009. A unique virulence factor for proliferation and dwarfism in plants identified from a phytopathogenic bacterium. Proc. Natl. Acad. Sci. U.S.A. 106:6416-6421.

Jameson, P. E. 2000. Cytokinins and auxins in plant-pathogen interactions-an overview. Plant Growth Regul. 32:369-380.

Jiu, M., Zhou, X. P., and Tong, L. 2007. Vector-virus mutualism accelerates population increase of an invasive whitefly. PLoS ONE 2:e182. Published online.

Johansen, B. 1990. Incompatibility in Dendrobium (Orchidaceae). Bot. J. Linn. Soc. 103:165-196.

Kaufmann, K., Muino, J. M., and Jauregui, R. 2009. Target genes of the MADS transcription factor SEPALLATA3: Integration of developmental and hormonal pathways in the Arabidopsis flower. PLoS Biol. 7:854-875.

Kitamura, Y., Hosokawa, M., Uemachi, T., and Yazawa, S. 2009. Selection of $\mathrm{ABC}$ genes for candidate genes of morphological changes in hydrangea floral organs induced by phytoplasma infection. Sci. Hortic. 122:603-609.

Ko, H. C., and Lin, C. P. 1994. Development and application of cloned DNA probes for a mycoplasma-like organism associated with sweet potato witches'-broom. Phytopathology. 84:468-473. 
Krizek, B. A., and Fletcher, J. C. 2005. Molecular mechanisms of flower development: An armchair guide. Nat. Rev. Genet. 6:688-698.

Kuske, C. R., and Kirkpatrick, B. C. 1992. Distribution and multiplication of western aster yellows mycoplasma-like organisms in Catharanthus roseus as determined by DNA hybridization analysis. Phytopathology 82:457-462.

Lee, C., Lee, S., Shin, S. G., and Hwang, S. 2008. Real-time PCR determination of rRNA gene copy number: Absolute and relative quantification assays with Escherichia coli. Appl. Microbiol. Biotechnol. 78:371-376

Lee, I. M., Davis, R. E., and Gundersen-Rindal, D. E. 2000. Phytoplasma: Phytopathogenic mollicutes. Annu. Rev. Microbiol. 54:221-255.

Liu, C., Xi, W. Y., Shen, L. S., Tan, C. P., and Yu, H. 2009. Regulation of floral patterning by flowering time genes. Dev. Cell 16:711-722.

Malcomber, S. T, and Kellogg, E. A. 2005. SEPALLATA gene diversification: Brave new whorls. Trends Plant Sci. 10:427-435.

Michaels, S. D. 2009. Flowering time regulation produces much fruit Curr. Opin. Plant Biol. 12:75-80.

Moyroud, E., Kusters, E., Monniaux, M., Koes, R., and Percy, F. 2010 LEAFY blossoms. Trends Plant Sci. 15:346-352.

Okamuro, J. K., Denboer, B. G. W., Lotysprass, C., Szeto, W., and Jofuku, K. D. 1996. Flowers into shoots: photo and hormonal control of a meristem identity switch in Arabidopsis. Proc. Natl. Acad. Sci. U.S.A. 93:13831-13836.

Ordidge, M., Chiurugwi, T., Tooke, F., and Battey, N. H. 2005. LEAFY, TERMINAL FLOWER1 and AGAMOUS are functionally conserved but do not regulate terminal flowering and floral determinacy in Impatiens balsamina. Plant J. 44:985-1000.

Parcy, F., Nilsson, O., Busch, M. A., Lee, I., and Weigel, D. 1998. A genetic framework for floral patterning. Nature 395:561-566.

Pelaz, S., Ditta, G. S., Baumann, E., Wisman, E., and Yanofsky, M. F 2000. B and C floral organ identity functions require SEPALLATA MADS-box genes. Nature 405:200-203.

Pelaz, S., Gustafson-Brown, C., Kohalmi, S. E., Crosby, W. L., and Yanofsky, M. F. 2001. APETALA1 and SEPALLATA3 interact to promote flower development. Plant J. 26:385-394.
Pouteau, S., Nicholls, D., Tooke, F., Coen, E., and Battey, N. 1997. The induction and maintenance of flowering in Impatiens. Development 124:3343-3351.

Pracros, P., Renaudin, J., Eveillard, S., Mouras, A., and Hernould, M. 2006. Tomato flower abnormalities induced by stolbur phytoplasma infection are associated with changes of expression of floral development genes. Mol. Plant-Microbe Interact. 19:62-68.

Seemuller, E., and Schneider, B. 2007. Differences in virulence and genomic features of strains of 'Candidatus Phytoplasma mali', the apple proliferation agent. Phytopathology 97:964-970.

Tan, P. Y., and Whitlow, T. 2001. Physiological responses of Catharanthus roseus (periwinkle) to ash yellows phytoplasmal infection. New Phytol. 150:757-769.

Teeri, T. H., Kotilainen, M., Uimari, A. Ruokolainen, S., Ng, Y. P., Malm, U., Pöllänen, E., Broholm, S., Laitinen, R., Elomaa, P., and Albert, V. A 2006. Floral developmental genetics of Gerbera (Asteraceae). Adv. Bot. Res. 44:323-351.

Tooke, F., Ordidge, M., Chiurugwi, T., and Battey, N. 2005. Mechanisms and function of flower and inflorescence reversion. J. Exp. Bot. 56:2587-2599.

Tran-Nguyen, L. T. T., Kube, M., Schneider, B., Reinhardt, R., and Gibb, K. S. 2008. Comparative genome analysis of "Candidatus Phytoplasma australiense" (subgroup tuf-Australia I; $r p-A$ ) and " $\mathrm{Ca}$. Phytoplasma asteris" strains OY-M and AY-WB. J. Bacterio. 190:3979-3991.

Vandenbussche, M., Zethof, J., and Souer, E. 2003. Toward the analysis of the petunia MADS box gene family by reverse and forward transposon insertion mutagenesis approaches: B, C, and D floral organ identity functions require SEPALLATA-like MADS box genes in petunia. Plant Cell 15:2680-2693.

Weintraub, P. G., and Beanland, L. 2006. Insect vectors of phytoplasmas. Annu. Rev. Entomol. 51:91-111.

Yang, J. Y., Iwasaki, M., Machida, C., Machida, Y., Zhou, X. P., and Chua, N. H. 2008. $\beta C 1$, the pathogenicity factor of TYLCCNV, interacts with AS1 to alter leaf development and suppress selective jasmonic acid responses. Gene Dev. 22:2564-2577. 